\title{
Reducing pulsewidth broadening in L-band EDFAs by use of a new L-band EDF
}

\author{
Yu, Jianjun; Jeppesen, Palle; Palsdottir, Bera; Knudsen, Stig Nissen
}

Published in:

I E E E Photonics Technology Letters

Link to article, DOI:

$10.1109 / 68.930404$

Publication date:

2001

Document Version

Publisher's PDF, also known as Version of record

Link back to DTU Orbit

Citation (APA):

Yu, J., Jeppesen, P., Palsdottir, B., \& Knudsen, S. N. (2001). Reducing pulsewidth broadening in L-band EDFAs by use of a new L-band EDF. I E E E Photonics Technology Letters, 13(7), 654 - 656.

https://doi.org/10.1109/68.930404

\section{General rights}

Copyright and moral rights for the publications made accessible in the public portal are retained by the authors and/or other copyright owners and it is a condition of accessing publications that users recognise and abide by the legal requirements associated with these rights.

- Users may download and print one copy of any publication from the public portal for the purpose of private study or research.

- You may not further distribute the material or use it for any profit-making activity or commercial gain

- You may freely distribute the URL identifying the publication in the public portal 


\title{
Reducing Pulsewidth Broadening in L-Band EDFAs by Use of a New L-Band EDF
}

\author{
Jianjun Yu, Palle Jeppesen, Bera Palsdottir, and Stig N. Knudsen
}

\begin{abstract}
Due to a small effective area of erbium-doped fiber (EDF), a short pulse will be broadened because of self-phase modulation when it is amplified in an L-band EDF amplifier (EDFA); hence, it is necessary to develop a new EDF with large $\mathrm{Er}^{3+}$ concentration to reduce the EDF length and a large effective area to reduce the nonlinear effect in the L-band EDFA. In this letter, it will be demonstrated that the pulsewidth can be maintained when a short pulse is amplified in an L-band EDFA consisting of a new L-band EDF.
\end{abstract}

Index Terms-Erbium-doped fiber, L-band erbium-doped fiber amplifier, self-phase modulation, wavelength conversion.

\section{INTRODUCTION}

$\mathbf{I}$ $\mathrm{N}$ ORDER to increase the transmission capacity, terabit wavelength-division multiplexed (WDM) systems using C-band (1530-1565 nm) and L-band (1565-1610 nm) erbium-doped fiber amplifiers (EDFAs) have already been presented [1]. The conventional erbium-doped fiber (EDF) is made with a small effective area and a large difference between the indexes of refraction in the core and cladding [2], [3]. Since the typical length of an EDF is only of the order of several tens of meters in a C-band EDFA, its nonlinear effect is very small. However, the length of an L-band EDFA is several times that of the C-band EDFA [4], [5] and this long length will lead to the fact that nonlinear effects can no longer be ignored. Recently, four-wave mixing (FWM) [2], [3] and XPM [6] in L-band EDFAs have been observed and investigated. Because nonreturn-to-zero (NRZ) signals were used in these references, the peak power was not so large, and consequently self-phase modulation (SPM) in the L-band EDFA was small. However, when a short pulse, for example of a duration of a few picoseconds, is amplified in an L-band EDFA, the pulsewidth will be broadened because of SPM. In this letter, we demonstrate for the first time, pulsewidth broadening in an L-band EDFA consisting of a conventional EDF and we also demonstrate that this broadening pulsewidth can be avoided when the pulse is amplified in an L-band EDFA consisting of a new L-band EDF. This new L-band EDF has a high $\mathrm{Er}^{3+}$ concentration and large effective area, which leads to the fact that the length of the EDF, and thereby, the nonlinear effect in L-band can be reduced.

Manuscript received January 19, 2001; revised April 5, 2001.

J. Yu was with the Research Center COM, Technical University of Denmark, DK-2800 Lyngby, Denmark. He is now with Agere Systems, Murray Hill, NJ 07974 USA.

P. Jeppesen is with the Research Center COM, Technical University of Denmark, DK-2800 Lyngby, Denmark.

B. Palsdottir and S. N. Knudsen are with Lucent Technologies Denmark, DK-2605 Brøndby, Denmark.

Publisher Item Identifier S 1041-1135(01)05604-X.

\section{EXPERIMENT}

\section{A. Gain Characteristics of the L-Band EDFA}

In [5], the L-band amplifier consists of a conventional C-band amplifier followed by a length of EDF. An external cavity laser (ECL) provides signal wavelength tunability from 1530 to1620 $\mathrm{nm}$. The signal power level is adjusted using an attenuator at the input of the C-band/L-band amplifier (OSA). At the output of the EDF, the signal power is measured using an optical spectrum analyzer. The conventional C-band EDFA is based on a counter-propagating 980-nm dual-pumping no-residual pump that could be observed at the output of the EDFA. Two kinds of EDFs are used: conventional EDF and new L-band EDF. The conventional EDF is $\mathrm{Al}$ and La codoped with a cutoff wavelength at $953 \mathrm{~nm}$ and it is doped with $\mathrm{Er}^{3+}$ to a level corresponding to an absorption of $7.4 \mathrm{~dB} / \mathrm{m}$ at the $1.53-\mu \mathrm{m}$ absorption peak. The background loss of the EDF measured at 1200 $\mathrm{nm}$ is $<12 \mathrm{~dB} / \mathrm{km}$. The effective area is $17.5 \mu \mathrm{m}^{2}$. The dispersion at $1550 \mathrm{~nm}$ is $2 \mathrm{ps} /(\mathrm{nm} \cdot \mathrm{km})$. The new L-band EDF is Al and La co-doped with a cutoff wavelength at $924 \mathrm{~nm}$ and it is doped with $\mathrm{Er}^{3+}$ to a level corresponding to an absorption of $20.4 \mathrm{~dB} / \mathrm{m}$ at the $1.53 \mu \mathrm{m}$ absorption peak. The background loss of this new L-band EDF measured at $1200 \mathrm{~nm}$ is $<10 \mathrm{~dB} / \mathrm{km}$. The effective area is $20 \mu \mathrm{m}^{2}$. The dispersion at $1550 \mathrm{~nm}$ is 1.5 $\mathrm{ps} /(\mathrm{nm} \cdot \mathrm{km})$. Because the absorption value is increased, the length is chosen to only $50 \mathrm{~m}$, while the length of the conventional EDF is 100 or $130 \mathrm{~m}$. The lengths of the EDFs were not optimized.

Fig. 1(a) shows that the amplified spontaneous emission (ASE) shift toward the L-band region induced by ASE pumping from the EDFA for both the conventional EDF and the new L-band EDF. Fig. 1(b) shows the small signal gain characteristics when the input signal is $-25 \mathrm{dBm}$. Gain of the order of $28 \mathrm{~dB}$ is obtained from 1575 to $1600 \mathrm{~nm}$ for both the conventional EDF and the new L-band EDF. Fig. 1(a) shows that the length of the new L-band EDF can be reduced because its peak wavelength is shifted to a long wavelength at $1600 \mathrm{~nm}$. A shorter L-band EDF will give flatter gain because the effective length of the L-band fiber is longer than the C-band fiber. For an input signal power of $-20 \mathrm{dBm}$, the ASE noise figure of the L-band EDFAs from $1570-1600 \mathrm{~nm}$ is $4-5.5 \mathrm{~dB}$ independently of the kind of EDF, but dependent on the signal wavelength.

\section{B. Pulsewidth Broadening in an L-Band EDFA Consisting of a Conventional EDF}

Short pulses with $10-\mathrm{GHz}$ repetition frequency, 1568-nm wavelength, $13-\mathrm{dBm}$ average power, and a full-width at half-maximum (FWHM) pulsewidth of $2.3 \mathrm{ps}$ are generated 


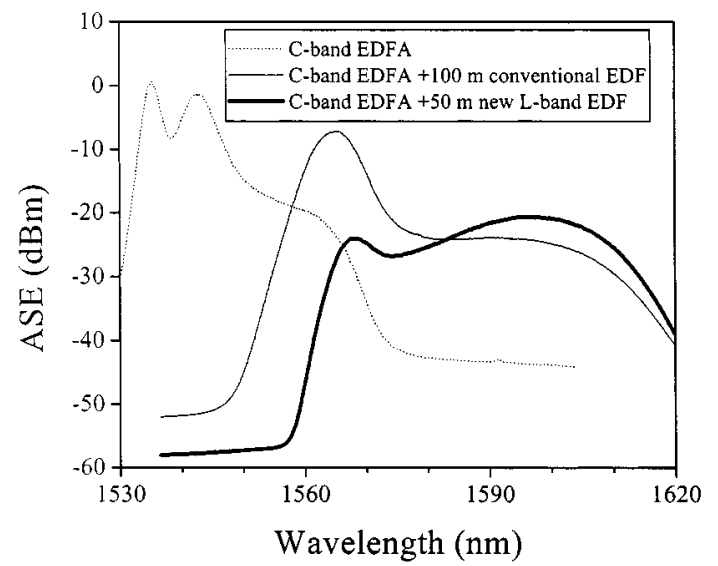

(a)

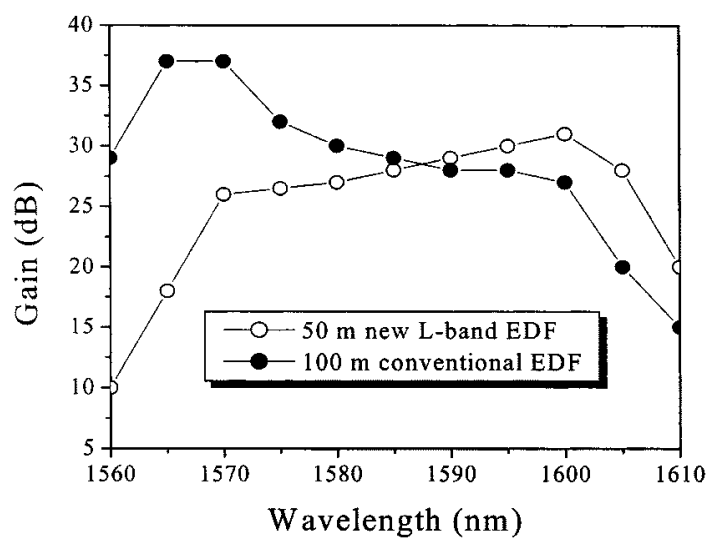

(b)

Fig.1. Optical spectral characteristics. (a) ASE shift from C-band to L-band induced in EDF. (b) Small-signal gain.

from a commercial erbium-fiber ring laser with $1568 \mathrm{~nm}$ as the longest possible wavelength. The short pulse was amplified by 130-m conventional EDF that was pumped by a conventional C-band EDFA, giving up to $14 \mathrm{dBm}$ of output power. Fig. 2 shows the experimental results. Because the EDF length in the C-band EDFA is only a few meters, the SPM effect in the C-band EDFA is very small and the pulsewidth and optical spectrum of the short pulses are not changed after the C-band EDFA. However, after 130-m EDF, the pulsewidth is broadened to 9.9-ps FWHM and the optical spectrum is also broadened. When 2.3-ps short pulse propagates over 130-m EDF, the pulse is broadened to $2.4 \mathrm{ps}$ only if the dispersion effect is considered; this clearly shows that the dispersion effect in the EDF plays a small role, however, the pulse will be broadened when combining SPM and dispersion, as shown in our experimental result.

\section{Comparing Pulsewidths for L-Band EDFAs Consisting of Different Kinds of EDFs}

In this section, we will experimentally investigate the pulsewidth when the short pulse is amplified by L-band EDFAs consisting of different kinds of EDFs. The experimental setup is shown in Fig.3. We use wavelength conversion based on a nonlinear optical loop mirror (NOLM) to obtain pulses with different wavelengths at L-band [7]. The control laser is a

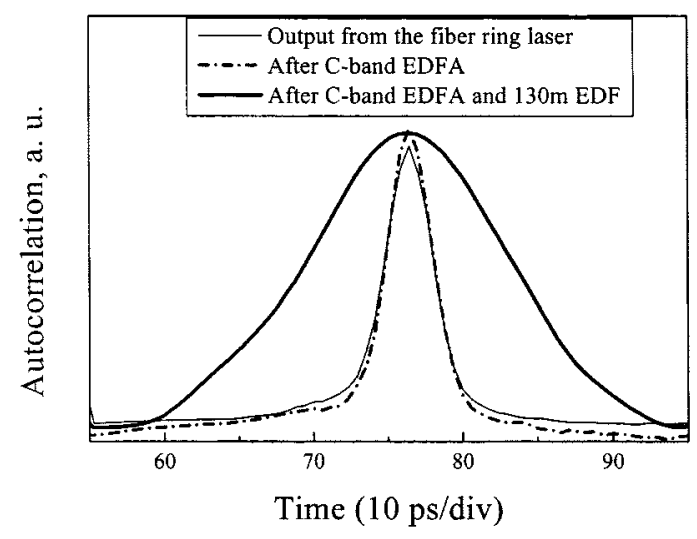

(a)

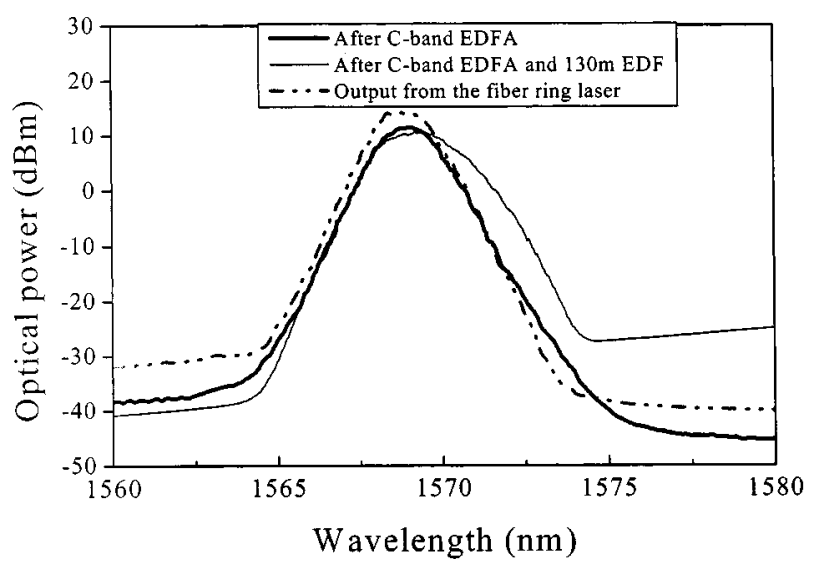

(b)

Fig. 2. Optical pulse characteristics. (a) Autocorrelator traces. (b) Optical spectra.

10-GHz 1560.6-nm gain-switched DFB-LD that generates 9.3-ps FWHM pulses after compression in a dispersion compensating fiber (DCF). In addition, we use a comb-dispersion profiled fiber (CDPF) to further compress the width of the control pulses to 2.4 ps. The control pulses are coupled into the NOLM using a wavelength independent 3-dB optical coupler. The continuous wave $(\mathrm{CW})$ lightwave is generated from an ECL. The CW lightwave having a wavelength in the 1530-1568-nm range is amplified to an average power of $14 \mathrm{dBm}$ by a conventional C-band EDFA. A CW lightwave between $1570-1580 \mathrm{~nm}$ was also generated by the ECL but was amplified by 130-m EDF that was pumped by a conventional C-band EDFA, giving up to $14 \mathrm{dBm}$ of output power. A $1.5-\mathrm{nm}$ bandpass TOF at the output of the NOLM is used to suppress the control pulses. The average power of the converted pulses after the TOF is $-15 \mathrm{dBm}$. The length of the HNL-DSF in the NOLM used for wavelength conversion is $0.5 \mathrm{~km}$. The zero dispersion wavelength, dispersion slope, and the nonlinear coefficient of this HNL-DSF are $1552 \mathrm{~nm}, 0.022 \mathrm{ps} / \mathrm{nm}^{2} / \mathrm{km}$, and $10.9 \mathrm{~W}^{-1} \mathrm{~km}^{-1}$, respectively. The L-band converted pulses are amplified by $100-$ or $130-\mathrm{m}$ conventional EDF or by $50-\mathrm{m}$ new L-band EDF pumped by a conventional C-band EDFA.

The measured FWHM-pulsewidth of the converted pulses as a function of wavelength of the $\mathrm{CW}$ lightwave is shown in Fig. 4. We assume that the waveforms of the converted pulses 


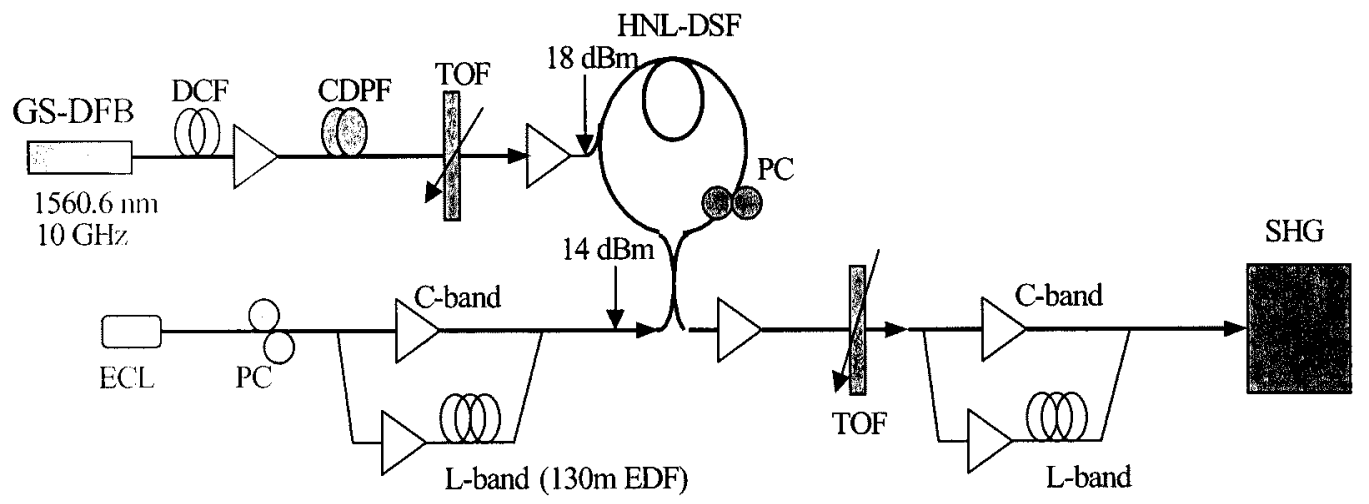

Fig. 3. Experimental setup for generation of short pulses at different wavelengths. GS-DFB-LD: Gain-switched distributed feedback laser diode. DCF: Dispersion compensating fiber. CDPF: Comb-dispersion profiled fiber. TOF: Tunable optical filter. HNL-DSF: High-nonlinearity dispersion shifted fiber. PC: Polarization controller. SHG: Second harmonic generation.

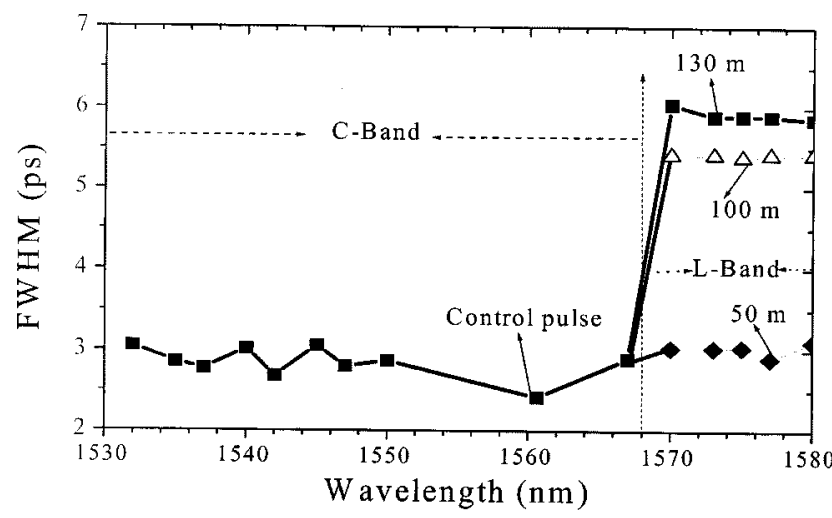

Fig. 4. FWHM pulsewidth of converted pulses as a function of $\mathrm{CW}$ wavelength, and SHG traces of converted pulses at $1575 \mathrm{~nm}$ by L-band EDFA consisting of different kinds of EDFs.

have Gaussian shape, so that the FWHM pulsewidth is equal to the second-harmonic generation (SHG) auto-correlation trace pulsewidth divided by $\sqrt{2}$. Observing Fig. 4 , we can see that the pulsewidth is approximately 3 ps when the CW lightwave wavelength is varied from 1532 to $1567 \mathrm{~nm}$. The slightly broadened pulsewidth is caused by the limited bandwidth of the optical filter. Our experiment shows that when a short pulse with a pulsewidth of 2.4 ps passes through an optical filter with a bandwidth of $1.5 \mathrm{~nm}$, the pulsewidth will be broadened to approximately $3 \mathrm{ps}$. However, in the L-band, the pulsewidth is about $6 \mathrm{ps}$ and almost constant, when the 130-m conventional EDF is used. The pulsewidth after the L-band EDFA at $1575 \mathrm{~nm}$ is $5.9 \mathrm{ps}$, while the pulsewidth after the C-band EDFA at $1534 \mathrm{~nm}$ is only $2.7 \mathrm{ps}$. Although the change in walkoff time from 1570 to 1580 $\mathrm{nm}$ is large, the width of the converted pulses is almost constant; this shows that the walkoff in this wavelength range only has a small effect on the width of the converted pulses. If there were no SPM in the L-band EDFA, and because the walkoff effect in the NOLM can almost be ignored, the pulsewidth after wavelength conversion at $1573 \mathrm{~nm}$ should also be $2.7 \mathrm{ps}$, but it is actually 5.9 ps. This shows that the pulsewidth after the L-band EDFA based on a conventional EDF is broadened. When the conventional EDF with a length of $100 \mathrm{~m}$ is used, the pulsewidth is about 5.4 ps and almost constant. However, when the new
L-band EDF with a length of $50 \mathrm{~m}$ is used, the pulsewidth is 3 ps. This demonstrates that SPM has a very small effect when the new L-band EDF is used.

\section{CONCLUSION}

We have observed that 2.3-ps optical pulses are broadened to several times that of the input pulsewidth after amplification in an L-band EDFA consisting of a conventional EDF; this observation implies that a short pulse with pulsewidths smaller than 3 ps should not be amplified by such an L-band EDFA. A new L-band EDF with a large $\mathrm{Er}^{3+}$ concentration and a large effective area has been designed and used in a new L-band EDFA. Our experimental results show that a short pulse amplified by the new L-band EDFA will not be broadened, which means that the broadening effect that was caused by SPM has been eliminated.

\section{REFERENCES}

[1] C. Scheerer, C. Glingener, A. Farbert, J. P. Elbers, A. Schropflin, E. Gottwald, and G. Fischer, "3.2Tbit/s $(80 \times 40 \mathrm{~Gb} / \mathrm{s})$ bidirectional WDM/ETDM transmission over $40 \mathrm{~km}$ standard single mode fiber," Electron. Lett., vol. 35, no. 20, pp. 1752-1753, 1999.

[2] S. Tadic, G. Pendock, A. Srivastava, P. Wysocki, and A. Chraplyvy, "Signal impairment due to four-wave mixing in L-band EDFAs," in 25th Eur. Conf. Optical Communication, Nice, France, 1999, Paper PD1-11.

[3] Y. Liu, S. Burtsev, S. Tsuda, S. P. Hegarty, R. S. Mozdy, M. Hempstead, G. G. Luther, and R. G. Smart, "Four-wave mixing in EDFAs," Electron. Lett., vol. 35, no. 24, pp. 2130-2131, 1999.

[4] H. S. Chung, M. S. Lee, D. Lee, N. Park, and D. J. Digiovanni, "Low noise, high efficiency L-band EDFA with 980-nm pumping," Electron. Lett., vol. 35, no. 13, pp. 1099-1090, 1999.

[5] A. Buxens, H. N. Poulsen, A. T. Clausen, and P. Jeppesen, "Gain flattened L-band EDFA based on upgraded C-band EDFA using forward ASE pumping in an EDF section," Electron. Lett., vol. 36, no. 9, pp. $156-158,2000$

[6] M. Shtaif, M. Eiselt, R. W. Tkach, R. H. Stolen, and A. H. Gnauck, "Crosstalk in WDM systems caused by cross-phase modulation in erbium-doped fiber amplifiers," IEEE Photon. Technol. Lett., vol. 10, pp. 1796-1798, Dec. 1998.

[7] J. Yu, Y. Qian, A. T. Clausen, H. N. Poulsen, P. Jeppesen, and S. N. Knudsen, "40 Gbit/s pulsewidth-maintained wavelength conversion based on a high-nonlinearity DSF-NOLM," Electron. Lett., vol. 36, no. 19, pp. 1633-1635, 2000.

[8] J. Yu, X. Zheng, C. Peucheret, A. T. Clausen, H. N. Poulsen, and P. Jeppesen, "All-optical wavelength conversion of short pulses and NRZ signals based on a nonlinear optical loop mirror," J. Lightwave Technol., vol. 18, pp. 1007-1017, July 2000. 